\title{
A review of precipitation isotope studies in China: Basic pattern and hydrological process
}

\author{
ZHANG Mingjun, "WANG Shengjie \\ College of Geography and Environmental Science, Northwest Normal University, Lanzhou 730070, China
}

\begin{abstract}
In the paper, the development of precipitation isotope observation networks in China was reviewed, and recent achievements in isoscape and environmental effect of precipitation stable isotopes were summarized; the hydrological process studies based on precipitation isotopes in China during recent decade were also reviewed. In past decades, the spatial and seasonal patterns of precipitation isotopes have been investigated nationwide, especially after the participation in GNIP (Global Network of Isotopes in Precipitation) and the establishment of CHNIP (Chinese Network of Isotopes in Precipitation), although long-term measurements are still limited; besides the nationwide network, a series of regional networks has been widely established across China. From the traditional manual drawing to the computer-aided mapping, and then to the simulation using isotope-equipped models, the productions of precipitation isoscape have been improved. The main factors controlling precipitation isotopes were summarized, and the potential significances of isotopes in climate proxies were mentioned. The recent studies about influence of raindrop sub-cloud secondary evaporation on isotopes were reviewed; based on the precipitation isotope and other parameters, the contribution of recycled moisture (evaporation and transpiration) in local precipitation can be estimated using three- or two-component mixing models. Finally, some prospects of precipitation isotope studies in China were presented.
\end{abstract}

Keywords: stable isotope; precipitation; China; isoscape; hydrological process

\section{Introduction}

Precipitation plays an important role in global water cycle, and the stable hydrogen and oxygen isotopes of precipitation provide useful information in hydrological processes. Since the establishment of the Global Network of Isotopes in Precipitation (GNIP) by International Atomic Energy Agency (IAEA) and World Meteorological Organization (WMO) in the mid-20th century, the stable isotopes in precipitation have been widely applied in moisture source region diagnosis, evaporation flux estimation, paleoclimate reconstruction and other aspects (Zheng and Chen, 2000; Gu, 2011; Lin, 2013). Because of the complex landform and moisture transport paths, the spatial distribution and seasonal variation of precipitation iso-

Received: 2016-01-04 Accepted: 2016-03-15

Foundation: National Natural Science Foundation of China, No.41461003, No.41161012; National Basic Research Program of China, No.2013CBA01801

Author: Zhang Mingjun, Professor, specialized in climate change and hydrological cycle. E-mail: mjzhang2004@163.com

*Corresponding author: Wang Shengjie, PhD, E-mail: geowang@126.com 
topes shows a great diversity in China. During recent decades, precipitation isotopes in China have been widely studied, and a great deal of meaningful information was acquired from the observations and simulations.

In the paper, a brief history of precipitation isotope observation on national and regional scales in China was reviewed in Section 2; the technical development of precipitation isoscape production was summarized as three stages in Section 3; the main factors influencing precipitation isotopes as well as the environmental significances of isotopes in climate proxies were analyzed in Section 4; some recent studies about moisture recycling and sub-cloud secondary evaporation using precipitation isotopic methods were reviewed in Section 5; finally, some prospects in future studies on precipitation isotopes were presented in Section 6.

\section{Brief history of isotope observation}

\subsection{Nationwide network}

The early studies of stable hydrogen and oxygen isotopes in China's precipitation dated back to the field investigation of Mount Qomolangma in the Himalayas Mountains during 1966-1968 (Zhang et al., 1973). After that, although precipitation stable isotopes were reported in Beijing (Wei et al., 1982) and other sites, the nationwide network in China was absent for a long period. Based on the precipitation samples collected at eight meteorological stations (Beijing, Nanjing, Guangzhou, Kunming, Wuhan, Xi'an, Lhasa and Urumqi) in 1980 (Figure 1a), Zheng et al. (1983) analyzed the main pattern of stable isotopes in precipitation of China, and the first national meteoric water line of China was determined as $\delta \mathrm{D}=7.9 \delta^{18} \mathrm{O}+8.2\left(r^{2}=0.95, n=101\right)$. Although the sampling frequency for each station was not exactly the same, this paper was the first nationwide investigation about spatial distribution of precipitation isotopes in China.

The IAEA periodically released technique reports of Environmental Isotope Data: World Survey of Isotope Concentration in Precipitation since the 1960s, but the vast land of China was not well covered during the initial three decades, except a coastal station Hong Kong (IAEA/WMO, 2015). In the 1980s, some research institutes in China tried to contact IAEA, and precipitation samples or measured isotopic data were gradually submitted to GNIP. In the published issue covering GNIP data in 1984-1987 (IAEA, 1990), the monthly isotopic

(a) Zheng et al. (1983)

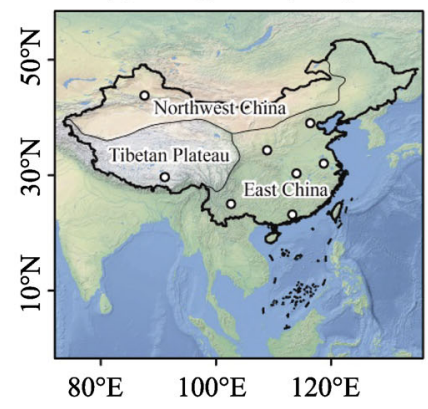

(b) GNIP (IAEA/WMO, 2015)

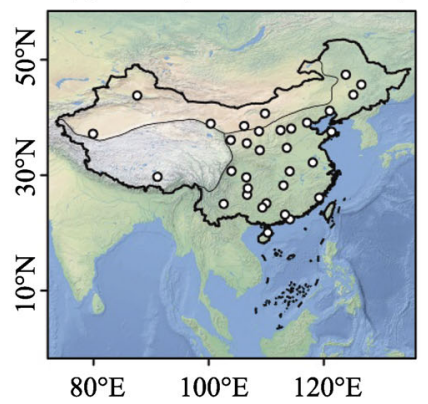

(c) CHNIP (Liu J et al., 2014a)

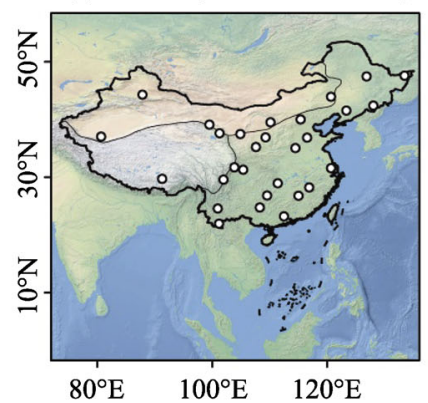

Figure 1 Spatial distribution of nationwide network for precipitation isotopes in China 
data in Shijiazhuang, Kunming, Xi'an and Guangzhou were included (Zhang, 1989); in the issue covering the 1988-1991 data (IAEA, 1994), more stations were added, including Guilin (Liu et al., 1987; Tu et al., 2004) as well as Qiqihar, Hotan, Yinchuan, Tianjin, Lhasa, Changsha, Guiyang, Nanjing, Fuzhou and Haikou (Zhao et al., 1995). Much more isotopic data were released later as a part of the GNIP database (Zhang et al., 1991; Liu et al., 1997a, 1997b). Shown in Figure 1b, there were a total of 33 sampling stations with monthly frequency in China, and there were 27 stations with monthly $\delta^{18} \mathrm{O}$ data no less than 24 months (IAEA/WMO, 2015). Using the annual weighted isotopic data in precipitation at 20 GNIP stations ( $\mathrm{Gu}, 2011)$, the meteoric water line of China was $\delta \mathrm{D}=7.7 \delta^{18} \mathrm{O}+7.0(n=20)$. Based on all the monthly data at 33 stations available (IAEA/WMO, 2015), the meteoric water line of China was determined as $\delta \mathrm{D}=7.5 \delta^{18} \mathrm{O}+6.1\left(r^{2}=0.94, n=2299\right)$.

However, all the GNIP stations in China suspended observations in the early 2000s, except Hong Kong (IAEA/WMO, 2015). In order to continue systematic observations nationwide, a new observation network named the Chinese Network of Isotopes in Precipitation (CHNIP) was established based on the Chinese Ecosystem Research Network (CERN) in 2004 (Figure 1c), and precipitation was monthly sampled and then analyzed for stable hydrogen and oxygen isotopes (Song et al., 2007). Using the observations at the initial years of CHNIP, Liu J et al. $(2008,2009,2010)$ analyzed the regional patterns of isoscape in China. Based on the observations at 29 CHNIP stations from 2005 to 2010, Liu J et al. (2014) reviewed the main pattern of precipitation isotope in China, and presented a comparison between CHNIP and GNIP. Based on the CHNIP during 2005-2010 (Liu J et al., 2014), a recent meteoric water line of China was determined as $\delta \mathrm{D}=7.48 \delta^{18} \mathrm{O}+1.01\left(r^{2}=0.94, n=928\right)$.

\subsection{Regional network}

To investigate the precipitation isotopes for a specific region, the existing nationwide observation networks are usually not enough. With the rapid development of measurement instrument, precipitation isotopes were analyzed in a number of sites across China in recent years. Here we summarized the recent measurements of precipitation isotopes for each natural zone in China.

(1) Cold area of the Tibetan Plateau

The Tibetan Plateau with a mean altitude $>4000 \mathrm{~m}$ a.s.l. covers a vast area in China, but the in-situ observation in the GNIP and CHNIP database is always limited (see Figures $1 \mathrm{~b}$ and 1c). To improve the knowledge for this region, an observation platform, later named as the Tibetan Plateau Network of Isotopes in Precipitation (TNIP), was established (Yao et al., 2013), and a great number of isotope studies have been carried out based on TNIP (e.g., Tian et al., 2007, 2008; Yu et al., 2007, 2008, 2009, 2015a, 2015b, 2016; Liu Z et al., 2007, 2008b, 2010; Gao et al., 2009, 2011; Wen et al., 2012; Ren et al., 2013). An earlier review of TNIP was presented by Yu et al. (2006). Based on the long-term TNIP observations and simulations, Yao et al. (2013) reviewed the climatic controls on stable oxygen isotope in precipitation across the Tibetan Plateau, and demonstrated that the northern and southern portions are dominated by the westerly and monsoon moisture, respectively. In addition, the Qilian Mountains at the northeastern margin (e.g., Zhang and Wu, 2007a, 2007b; Wang et al. 2008; Zhao et al., 2011b; Wu H et al., 2014a; Li Z et al., 2015a, 2015b; Cui and Li, 2015) and the Hengduan Mountains at the southeastern margin (e.g. Xu et al., 2006, 2008; Song et 
al., 2015) of the plateau have also been investigated in many studies.

(2) Arid area of Northwest China

In the arid area of Northwest China, the studies of precipitation isotopes mainly focused on the Tianshan Mountains and the Hexi Corridor. For the Tianshan Mountains, the upper and middle reaches of the Urumqi River Basin has aroused great interest, which made the small inland river basin a hot spot of precipitation isotope studies since the late 1990s (e.g., Yao et al., 1999; Hou et al., 1999; Zhang et al., 2003; Pang et al., 2011; Feng et al., 2013; Kong et al., 2013); the strong temperature effect as well as the processes affecting precipitation isotopes in this watershed was analyzed, but the isotope studies beyond this basin (e.g., Wang X et al., 2015) were scarce. In 2012, an observation network with more than 20 stations was established around the Tianshan Mountains, which was useful to understand the spatial pattern of precipitation isotopes across this region (Wang, 2015; Wang et al., 2016a, 2016b, 2016c). For the Hexi Corridor (sometimes referred to as the Extensive Hexi Region, including the Hexi Corridor and the Qilian Mountains), some studies were carried out (e.g., Wu et al., 2010, 2011; Ma J et al., 2012; Guo et al., 2015a), which were reviewed by $\mathrm{Hu}$ et al. (2014) and Guo et al. (2015b). Besides the Tianshan Mountains and the Hexi Corridor, studies on other parts were relatively limited (e.g., Wu J et al., 2012; Yin et al., 2011).

(3) Monsoon area of East China

For the northern portion of the monsoon area of East China (divided by the Qinling Mountains-Huaihe River Line), the precipitation isotopes at some experiment watersheds were analyzed, e.g., Liu et al. (2005) and Liu X et al. (2007). In the Beijing City, the precipitation isotopes have been discontinuously measured in the past decades (e.g., Wei et al., 1982; Zheng et al., 1983; Wen et al., 2010; Tao et al., 2013; Zhai et al., 2013; Li J et al., 2015); in the Lanzhou City, an intensive observation network has been implemented, which was useful to understand the micro climate controls on precipitation isotopes (Ma et al., 2014; Chen et al., 2015a, 2015b). In addition, a precipitation isotope network was recently established across the Haihe River basin, and seven sampling stations were included in this network (Pang et al., 2015; Zhao et al., 2015).

For the southern portion of this region, the precipitation isotopes have been reported at many cities, and seasonal pattern and moisture source were analyzed, including Changsha (Wu et al., 2015; Wu H et al., 2012, 2014b; Huang et al., 2013, 2015; Li G et al., 2015), Guangzhou (Xue et al., 2007, 2008; Xie et al., 2011; Yang et al., 2011; Yin et al., 2012; Liao et al. 2012), Guilin (Wu X et al., 2014; Zhang M et al., 2015), Nanjing (Tang et al., 2015), Chongqing (Li et al., 2010) and others (Zheng et al., 2009; Zhang et al., 2010; Chen et al., 2010). In addition, the in-situ observation of precipitation isotopes across the Taiwan Island was also reported by Peng et al. $(2010,2011,2012)$.

\subsection{Development of measurement technique}

The development of commercial measurement instrument for analyzing water stable isotopic ratios resulted in the availability of more and more data in hydrological and climate studies. Generally, the currently used measurement techniques in China include the isotope ratio mass spectrometer (IRMS) and the isotope ratio infrared spectroscopy (IRIS).

IRMS, as a traditional method, has been frequently applied to measure water stable isotopic ratios for a long period in China (e.g., Zheng et al., 1983; Liu et al., 1987; Yao et al., 
2013; Liu J et al., 2014). A brief development history of IRMS in the past decades as well as the typical commercial IRMS productions was introduced by Lin (2013), and the main types included dual-inlet IRMS, continuous flow IRMS, GC-C/TC-IRMS and so on. Yang et al. (2012) presented an inter-comparison of stable isotopes in sea water and groundwater using three commercial analyzers (Finnigan MAT253, MAT252 and Delta-plus).

In the past several years, IRIS has provided an important alternative to the traditional IRMS due to its ease of use, low cost and potential of fieldwork, which led to a rapid development of water isotope studies in China. As seen in the recent publications, there were three commercial IRIS productions, including: (1) off-axis integrated cavity output spectroscopy (OA-ICOS) by Los Gatos Research Inc., e.g., Wu et al. (2015); (2) wavelength-scanned cavity ring-down spectroscopy (WS-CRDS) by Picarro Inc., e.g., Tang et al. (2015); and (3) tunable diode laser absorption spectroscopy (TDLAS) by Campbell Scientific Inc., e.g., Wen et al. (2010). An inter-comparison of four commercial analyzers was carried out by Wen X et al. (2012), including analyzers from Campbell Scientific (TGA100A), Picarro (L1115-i and L1102-i) and Los Gatos Research (DLT-100). Comparisons of water isotopic analysis using IRMS and IRIS were also conducted by Zhao et al. (2011a), Liu et al. (2013) and Zhang L et al. (2015).

\section{Precipitation isoscape}

The spatial distribution of stable isotopes in precipitation, also known as isoscape, is important in isotope studies. To investigate the isoscape of precipitation in China on a national scale, great efforts have been made during the last decades. The development of isoscape productions corresponded to the establishment of observation network and the improvement of calculation approach. From the traditional manual drawing to the computer-aided mapping, and then to the simulation using isotope-equipped climate models, a series of isoscape productions in China has been released in the past. The main development stages were listed below:

(1) Simple spatial interpolation

Before the wide use of computer-aided interpolation technique especially for geographical information system (GIS), scientists have to manually draw the spatial distribution based on the known data at sampling sites (e.g., Yu and Li, 1997; Liu et al., 1997a; Zhang and Yao, 1998). For the regions without enough observations, some empirical relationship may be considered. Since the 2000s, computer-aided interpolation technique operated in ArcGIS, Surfer or other programs has been frequently applied in geography, which provided a practical approach to create precipitation isoscape (e.g., Luo et al., 2008; Li et al., 2014b). However, these simple spatial interpolation methods were still not very good at predicting the unmeasured sites at small scales, especially under a complex topography.

(2) Interpolation with spatial and climate variables

The precipitation isotopes are usually related to spatial variables (e.g., latitude, longitude and elevation) and/or climate variables (e.g., temperature) (Liu J et al., 2014). With the advanced support of GIS, these geographical and meteorological controls can be practically considered in isoscape productions. Based on a global isoscape model $\left(\delta^{18} \mathrm{O}=a|L|^{2}+b|L|+c A+\right.$ $d$, where $L$ and $A$ are latitude and altitude, respectively; sometimes called BW model) de- 
veloped by Bowen and Wilkinson (2002), Liu Z et al. (2008a, 2009) calculated precipitation isoscape in China with consideration of latitude and altitude, and then Yang et al. (2014) reevaluated the model. Zhao L et al. (2012) changed the altitude parameter to air temperature, and developed a new second-order regression for each month $\left(\delta^{18} \mathrm{O}=a L^{2}+b L+c T+d\right.$, where $L$ and $T$ are latitude and temperature, respectively). In addition, using an interpolation with a variable of surface air temperature, the precipitation isoscape in China was also calculated by Li et al. (2011c).

(3) Isotope-enabled climate model simulation

The in-situ measurements of precipitation isotopes can be incorporated to general circulation models (GCMs) or regional circulation models (RCMs), and the precipitation and vapor isoscape can be simulated at different spatial and temporal scales. In recent years, the stable isotope-enabled GCMs were widely used, which provided meaningful information about regime controlling precipitation isotopes in China (Yao et al., 2013). Generally, these published simulation studies can be classified into two types: (a) Reproduced using the global isotopic output released by the Stable Water Isotope Intercomparison Group (SWING) and its second stage (SWING2) (Risi et al., 2012), e.g., Zhang et al. (2012) based on SWING and Wang S et al. (2015) based on SWING2. (b) Simulated with local isotope input (mainly on the Tibetan Plateau), e.g., Gao et al. (2011, 2013, 2015, 2016), Yao et al. (2013), He et al. (2015a, 2015b). In addition, other models can also be used to generate isoscapes in China, such as the isotope Atmospheric Water Balance Model (iAWBM) (Zhang X P et al., 2015).

\section{Environmental significance of isotopes}

\subsection{Meteorological controls}

$\mathrm{Gu}$ (2011) summarized that the stable isotopes in precipitation are mainly influenced by three factors including water molecule characteristics (e.g., mass number and specific heat), moisture source region condition (e.g., location, vapor transport intensity and evaporative condition) and precipitation region condition (e.g., temperature effect, amount effect, latitude effect, altitude effect and continental effect). The factors controlling stable isotopes in precipitation are vital information, and the environmental effect of precipitation isotope aroused great attention in past decades.

The temperature and precipitation amount are major meteorological factors influencing stable isotopes in precipitation. The fractionation of isotopes during evaporation and condensation is related to air temperature. Figure 2 a shows the spatial distribution of correlation coefficients between stable oxygen isotope and air temperature based on the national and some regional networks (IAEA/WMO, 2015; Liu J et al., 2014; Yao et al., 2013). Across China, temperature effect at the northern portion is much more significant than that at the southern portion. Regarding the amount effect, the high correlation coefficients between $\delta^{18} \mathrm{O}$ and precipitation amount mainly occur at the southern portion of China (Figure $2 \mathrm{~b}$ ). In addition, a stepwise regression model was applied to the GNIP and CHNIP stations by Liu J et al. (2014), and the monthly value of $\delta^{18} \mathrm{O}$ in precipitation can be estimated using corresponding meteorological parameters including air temperature, precipitation amount, relative humidity, vapor pressure, sunshine duration, wind speed and direction. 
(a) Air temperature

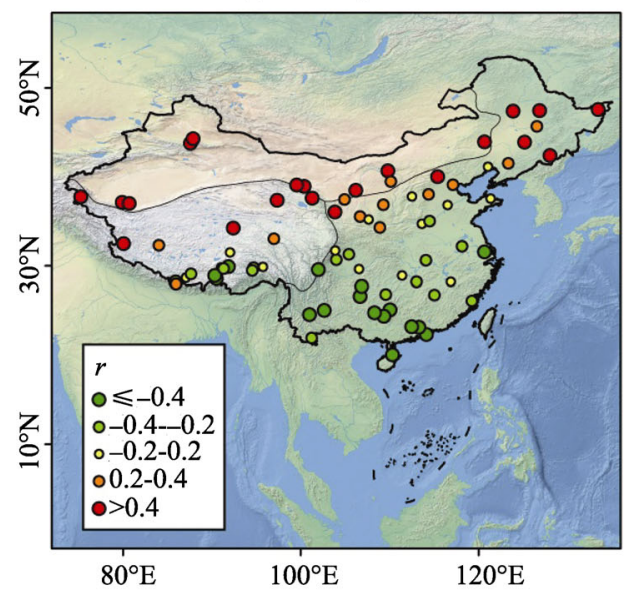

(b) Precipitation amount

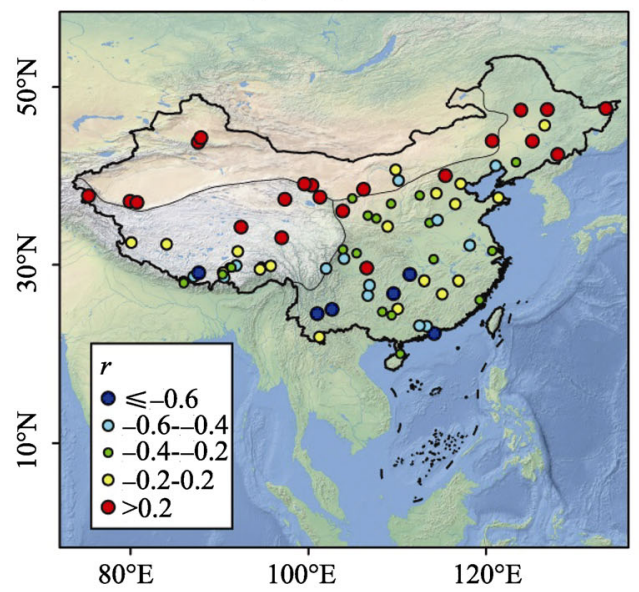

Figure 2 Spatial distribution of correlation coefficients between precipitation $\delta^{18} \mathrm{O}$ and meteorological parameters (a. air temperature, b. precipitation amount) in China (data are acquired from Yao et al., 2013; Liu J et al., 2014; IAEA/WMO, 2015)

The main moisture transport paths in China include the East Asian monsoon, the Indian monsoon and the Westerly, and the precipitations controlled by different source regions and atmospheric circulation patterns usually present different isotopic ratios (Zhang et al., 2004; Yu et al., 2014; Cai and Tian, 2016). In the Tibetan Plateau (Tian et al., 2007; Yao et al., 2013), the westerly-dominant regions (northern portion) showed enriched isotopes in summer and depleted isotopes in winter, but the Indian monsoon-dominant regions (southern portion) exhibited an obvious decreasing trend of $\delta^{18} \mathrm{O}$ from spring to summer. In eastern China (Tan and Nan, 2010; Tan, 2014; Huang et al., 2015), the intensity co-variation of moistures from the Indian and Pacific Oceans may lead to a variation of precipitation isotopes. In the Tianshan Mountains dominated by the westerly, Liu et al. (2015) analyzed the impact of moisture transport path on precipitation isotopes, and found an interannual difference in isotopes caused by the high and low latitude sources. In some event-based isotope studies, the influence of moisture source region was very sensitive (Pang et al., 2006). For instance, based on the rain samples collected during an extreme event (21-22 July, 2012, collected at frequencies between $10 \mathrm{~min}$ and $2 \mathrm{~h}$ ) in the Beijing City (Tao et al., 2013; Li et al., 2015), the contributions from southern and southeastern moistures were detected. In the Tianshan Mountains (Wang, 2015), the stable isotopes in event-based samples were considered to be related to the duration of moisture transport.

\subsection{Geographical controls}

As mentioned in Section 3, the variation of stable isotopes in precipitation is related to latitude and elevation (Liu Z et al., 2008a, 2009; Yang et al., 2014). Based on the CHNIP stations covering an elevation range from $3 \mathrm{~m}$ to $3688 \mathrm{~m}$ a.s.1., Liu J et al. (2014) presented a regression model as $\delta^{18} \mathrm{O}=8.892-0.041 L O N-0.312 L A T-0.002 A L T$ where $L O N, L A T$ and $A L T$ are longitude $\left({ }^{\circ}\right)$, latitude $\left(^{\circ}\right)$ and altitude $(\mathrm{m})$, and partial correlation coefficients are 0.040 , $0.369(p<0.05), 0.190(p<0.05)$, respectively. The gradient between precipitation $\delta^{18} \mathrm{O}$ and latitude was $-0.22 \%{ }^{\circ}$ based on CHNIP (Liu J et al., 2014), which was very similar to the 
GNIP-based result in eastern China $\left(-0.23 \%{ }^{\circ} ; \mathrm{Gu}, 2011\right)$.

Based on the CHNIP database, the linear gradient between precipitation $\delta^{18} \mathrm{O}$ and altitude was $-0.13 \% / 100 \mathrm{~m}$ in China, and the CHNIP sites across the Tibetan Plateau showed a much lower value $(-0.3 \% / 100 \mathrm{~m})$ than the nationwide result (Liu J et al., 2014). However, in the TNIP database (Yao et al., 2013), the gradients are $-0.17 \% / 100 \mathrm{~m}$ for the westerly-dominant portion and $-0.13 \%$ / $100 \mathrm{~m}$ for the monsoon-dominant portion of the Tibetan Plateau; Some other values are also reported in previous studies for this region (Yao et al., 2009). These different gradients between isotopic ratio and elevation are greatly related to the spatial and temporal representativeness of sampling stations.

\subsection{Isotopes as climate proxy}

If the stable isotopes in precipitation are well recorded in ice core, speleothems or other climate proxies, the climate information in the past can be reconstructed using the isotopic technique. During recent years, the relationship between $\delta^{18} \mathrm{O}$ in ice cores and surface air temperature have been widely investigated at many glaciers in China, e.g., Muztagata Glacier (Tian et al., 2006), Dunde Ice Cap (Yao and Thompson, 1992), Guliya Glacier (Yao et al., 1996), Malan Ice Cap (Wang et al., 2003), Puruogangri Glacier (Yao et al., 2006), Geladaindong Glacier (Kang et al., 2007), Noijin Kangsang Glacier (Zhao H et al., 2012), East Rongbuk Glacier (Zhang et al., 2005), Dasuopu Glacier (Yao et al., 2002) and Miaoergou Ice Cap (Song et al., 2011). Generally, for the ice cores drilled at the northern portion controlled by the westerlies, the temperature effect in ice cores was widely accepted, unless great elution occurred; however, for those at the southern portion controlled by monsoon moisture, the explanations of stable isotopes in ice cores were relatively complex. Zhao et al. (2014) reviewed the environmental significance of stable isotopes in 10 typical ice cores, and found that the normalized ice core $\delta^{18} \mathrm{O}$ positively correlated with air temperature for northern portion $(r=0.53)$ and southern portion $(r=0.44)$, respectively. In addition, to investigate the influence of post-deposition of the stable isotope in snow-firn-ice evolution, a series of field work was carried out at the Urumqi Glacier No. 1 in the Tianshan Mountains, e.g., Hou et al. (1999), Zhang et al. (2009), Li et al. (2011a, 2011b), Wang et al. (2011).

Besides the ice core studies, many investigations on environmental significance of speleothems isotopes were also carried out, and the isotopic evolutions from rainfall to drip water were observed across China, e.g., Luo et al. (2013, 2014), Wu X et al. (2014), Tan et al. (2015), Zeng et al. (2015). Luo et al. (2008) and Peng and Li (2012) reviewed some progress on this subject; the main conclusion was that the drip water isotopes is jointly influenced by precipitation isotopic ratio and local environment, and the explanations of monsoon intensity and circulation effect were popular in speleothems isotope studies.

\section{Sub-cloud evaporation and moisture recycling}

\subsection{Raindrop sub-cloud evaporation}

The sub-cloud secondary evaporation of falling raindrops may greatly influence the isotopic ratios, which makes $\delta$-value and D-excess in near-ground samples different from that below cloud base. In a study of water vapor isotopes in China derived from satellite measurements, Liu $\mathrm{Z}$ et al. (2014) found that below-cloud evaporation is a key driver causing the difference 
of isotopes from vapor to precipitation in non-monsoon regions. Usually, precipitation impacted by sub-cloud evaporation may show an enriched $\delta$-value and decreased D-excess, and the slope and intercept of meteoric water line also changes. The variations of isotopic ratio and meteoric water line under different meteorological conditions were frequently used to reflect the existence of sub-cloud evaporation (e.g., Meng and Liu, 2010; Wu et al., 2015; Chen et al., 2015b; Zhao et al., 2015).

The quantitative estimation of isotopic variation from cloud base to near-ground caused by sub-cloud process has aroused attentions in recent years. Using a cloud physics model, Zhang et al. (1998) simulated the variation of stable isotopes in raindrops; the results indicated that $\delta^{18} \mathrm{O}$ in falling raindrop gradually enriches through unsaturated air, but D-excess shows a decreasing-and-increasing trend with a transition height depending on relative humidity and raindrop size. Kong et al. (2013) used a model developed by Froehlich et al. (2008) to describe the D-excess variation from cloud base to ground, and presented a linear relationship that $1 \%$ of raindrop evaporation corresponds to approximately $1 \%$ of D-excess decrease, which coincided with previous report in the European Alps (Froehlich et al. 2008). However, the meteorological input in this model is not available for most studies, so the slope of $\sim 1 \%$ o $/ 1 \%$ was often applied to estimate the evaporation proportions (e.g., Peng et al., 2010; Ma et al., 2014; Chen et al., 2015b; Jin et al., 2015). It should be mentioned that the relationship of $\sim 1 \% / 1 \%$ are derived from a low evaporation condition with remaining fraction of raindrop mass $>95 \%$ (Kong et al., 2013; Froehlich et al. 2008), and more arid climate should be considered. Based on an observation network around the Tianshan Mountains, Wang et al. (2016b) calculated a wider range of remaining fraction from $\sim 0 \%$ to $100 \%$, and found that the correlations between D-excess difference and raindrop remaining fraction are relatively weak under a condition of high evaporation; under meteorological conditions of air temperature $\geq 20^{\circ} \mathrm{C}$ or relative humidity $<70 \%$, the regression coefficient is up to $\sim 1.5 \%$ o $1 \%$.

\subsection{Recycled moisture in precipitation}

The recycled moisture in precipitation denotes the precipitation sustained by evapotranspiration, including water vapor originating from evaporation and transpiration of land surface, and usually plays an important role in continental precipitation (Brubaker et al., 1993). In a conceptual model, the precipitating vapor can be assumed as an intensive mixture of advected and recycled vapor, and the contributions of advection, evaporation and transpiration in local precipitation can be calculated using isotopic ratios in each component (Peng et al., 2011). This type of models is sometimes called the three-component mixing model. It is clear that systemic measurements for stable isotopes in each water body (precipitation, vapor, surface water, plant, soil and others) are very useful to calculate the contribution of recycled moisture; however, the precipitation isotope is the vital input, and the isotopes in other carriers can be estimated using precipitation isotopes if necessary (e.g., Peng et al., 2011; Wang et al., 2016a).

The three-component mixing model has been applied in many regions in China during recent years (Table 1). Peng et al. (2011) calculated the contribution of locally recycled moisture in the Taiwan Island, and found that the contributions from advection, evaporation and transpiration are $58 \%-71 \%, 1 \%-2 \%$ and $28 \%-41 \%$, respectively. Ma Q et al. (2012) 
used a similar method to investigate the Tibetan Plateau, and showed that the contributions of recycled moisture have seasonal difference between summer and winter months. At the oasis sites near the Tianshan Mountains in Northwest China, Wang et al. (2016a) found that transpiration contribution at large oasis (like Urumqi) is much greater than that at small oasis. Generally, the relative contribution for each component is related to the surface meteorological conditions (especially air temperature and relative humidity), underlying surface landcover (vegetation, open water or others) and study domain.

Table 1 Contributions of each component ( $f_{\text {adv }}$-advection, $f_{\mathrm{ev}}$-evaporation and $f_{\mathrm{tr}}$-transpiration) in local precipitation in previous studies

\begin{tabular}{|c|c|c|c|c|c|c|}
\hline \multirow{2}{*}{ Model type } & \multirow{2}{*}{ Study region } & \multirow{2}{*}{ Months } & \multicolumn{3}{|c|}{ Contribution $(\%)^{*}$} & \multirow{2}{*}{ Reference } \\
\hline & & & $f_{\text {adv }}$ & $f_{\mathrm{ev}}$ & $f_{\mathrm{tr}}$ & \\
\hline \multirow{4}{*}{$\begin{array}{l}\text { Three-component } \\
\text { mixing model }\end{array}$} & Taiwan Island & Jun-Sep & $58-71$ & $1-2$ & $28-41$ & Peng et al. (2011) \\
\hline & Tib & Jun-Sep & $56-68$ & $5-12$ & $27-35$ & \multirow{2}{*}{ Ma et al. (2012b) } \\
\hline & Tibetan Plateau & Oct-May & $48-64$ & $1-6$ & $31-48$ & \\
\hline & Tianshan Mountains & Apr-Oct & $84-97$ & $1-6$ & $3-10$ & Wang et al. (2016a) \\
\hline \multirow{4}{*}{$\begin{array}{l}\text { Two-component } \\
\text { mixing model }\end{array}$} & Nam Co Lake, Tibetan Plateau & Jun-Sep & - & $28-31$ & - & Xu et al. (2011) \\
\hline & Tianshan Mountains & Jan-Dec & - & $0-8$ & - & Kong et al. (2013) \\
\hline & Southeast China & Jun-Sep & - & $1-4$ & - & Ma et al. (2013) \\
\hline & Qinghai Lake, Tibetan Plateau & Apr-Oct & - & 23 & - & Cui and Li (2015) \\
\hline
\end{tabular}

Note: $*$ The ranges of contribution denote values for different sampling sites or years, not different months.

In some cases that evaporation flux is considered to be significantly greater than transpiration flux (e.g., stations near large open water or covered by bare soil), the precipitating vapor can be assumed as a mixture of advection and evaporation vapors (excluding transpiration). This type of models is usually called the two-component mixing model. Xu et al. (2011) calculated the contribution of evaporation from the Nam Co Lake in the Tibetan Plateau using isotopic method, and found a proportion between $28.4 \%$ and $31.1 \%$ during the period 2005-2008. In another studies at the Qinghai Lake in the northeastern Tibetan Plateau (Cui and Li, 2015), the evaporation contribution from the lake was estimated to be $23.4 \%$ (equals $90.5 \mathrm{~mm}$ ), ranging from 3.0\% in October to $37.9 \%$ in August. Compared with lakeside sites, the evaporation contribution reported in other studies are usually much lower (e.g., Kong et al., 2013; Ma et al., 2013), and some mountainous stations even show a negligible contribution $(<0.1 \%)$.

\section{Summary and outlook}

The recent progress in precipitation stable isotope studies across China was reviewed in this study. During past decades, the nationwide observation network for precipitation isotopes has been established, which is important to investigate the main isotopic pattern in China. As analyzing technique develops in recent years, a great number of water isotopic data are available for scientific research, and the newly supplemented in-situ measurements greatly improve the knowledge at different areas. The main factors controlling precipitation stable isotopes in China was generally clear, especially for temperature and amount effects, although the environmental significance of isotopes at interdecadal and synoptic scales may 
need more studies. Based on the more and more in-situ observations, the precipitation isotope has been frequently used to estimate the recycled moisture in local precipitation as well as other aspects in hydrological and climate studies.

With the great improvements in research method and measurement technique, more hydrological process can be detected, and the following aspects should be focused on in future research. (1) The connection between stable isotopes in precipitation and water vapor. In recent years, the vapor isotopes across China have been continuously measured using isotopic ratio infrared spectroscopy at more and more sites as well as satellite techniques, which can remove the disadvantage of logical discontinuity in precipitation isotopic records. The different information of isotopes in precipitation and water vapor should be paid more attention. (2) Micro and synoptic scale diagnoses using isotopic method. The precipitation isotopic variations at a small domain or short time period were not well considered in the previous studies, but the information within the process at micro and synoptic scale is very useful in hydrological and climate research. (3) Potential of ${ }^{17} \mathrm{O}$ in precipitation. As a stable isotope of oxygen, ${ }^{17} \mathrm{O}$ has aroused great attention in recent years, mainly caused by the recent technique development. However, in the publication available, the studies on precipitation ${ }^{17} \mathrm{O}$ and ${ }^{17} \mathrm{O}$-excess across China are still nearly absent. (4) Wide use of isotope-enabled GCM simulations. The isotope-enabled GCMs in recent publications show good performance describing dynamical and microphysical processes, especially over the Tibetan Plateau, and this approach can be applied in a wider scope across China.

\section{References}

Bowen G J, Wilkinson B H, 2002. Spatial distribution of $\delta^{18} \mathrm{O}$ in meteoric precipitation. Geology, 30(4): 315-318.

Brubaker K L, Entekhabi D, Eagleson P S, 1993. Estimation of continental precipitation recycling. Journal of Climate, 6(6): 1077-1089.

Cai Z, Tian L, 2016. Atmospheric controls on seasonal and interannual variations in the precipitation isotope in the East Asian Monsoon region. Journal of Climate, 29(4): 1339-1352. doi: 10.1175/JCLI-D-15-0363.1.

Chen F, Zhang M, Ma Q et al., 2015a. Stable isotopic characteristics of precipitation in Lanzhou City and its surrounding areas, Northwest China. Environmental Earth Sciences, 73(8): 4671-4680.

Chen F, Zhang M, Wang S et al., 2015b. Relationship between sub-cloud secondary evaporation and stable isotope in precipitation of Lanzhou and surrounding area. Quaternary International, 380/381: 68-74.

Chen J, Cao J, Huang Y, 2010. The hydrogen and oxygen isotope composition of precipitation in the Xiamen coastal area. Journal of Marine Sciences, 28(1): 11-17. (in Chinese)

Cui B L, Li X Y, 2015. Stable isotopes reveal sources of precipitation in the Qinghai Lake Basin of the northeastern Tibetan Plateau. Science of the Total Environment, 527/528: 26-37.

Feng F, Li Z, Zhang M et al., 2013. Deuterium and oxygen 18 in precipitation and atmospheric moisture in the upper Urumqi River Basin, eastern Tianshan Mountains. Environmental Earth Sciences, 68(4): 1199-1209.

Froehlich K, Kralik M, Papesch W et al., 2008. Deuterium excess in precipitation of Alpine regions: Moisture recycling. Isotopes in Environmental and Health Studies, 44(1): 61-70.

Gao J, Masson-Delmotte V, Risi C et al., 2013. What controls precipitation $\delta^{18} \mathrm{O}$ in the southern Tibetan Plateau at seasonal and intra-seasonal scales? A case study at Lhasa and Nyalam. Tellus B, 65: 21043. doi: 10.3402/tellusb.v65i0.21043.

Gao J, Masson-Delmotte V, Yao T et al., 2011. Precipitation water stable isotopes in the South Tibetan Plateau: Observations and modeling. Journal of Climate, 24(13): 3161-3178.

Gao J, Risi C, Masson-Delmotte V et al., 2016. Southern Tibetan Plateau ice core $\delta^{18} \mathrm{O}$ reflects abrupt shifts in atmospheric circulation in the late 1970s. Climate Dynamics, 46(1): 291-302. doi: 10.1007/s00382-015-2584-3. 
Gao J, Shen S S P, Yao T et al., 2015. Reconstruction of precipitation $\delta^{18}$ O over the Tibetan Plateau since 1910. Journal of Geophysical Research: Atmospheres, 120(10): 4878-4888.

Gao J, Tian L, Liu Y et al., 2009. Oxygen isotope variation in the water cycle of the Yamzho Lake Basin in southern Tibetan Plateau. Chinese Science Bulletin, 54(16): 2758-2765.

$\mathrm{Gu}$ W, 2011. Isotope Hydrology. Beijing: Science Press. (in Chinese)

Guo X, Feng Q, Li Z et al. 2015a. Variation of stable isotopes and moisture sources in precipitation at the Dunhuang Basin in Northwest China. Journal of Desert Research, 35(3): 715-723. (in Chinese)

Guo X, Feng Q, Wei Y et al., 2015b. An overview of precipitation isotopes over the Extensive Hexi Region in NW China. Arabian Journal of Geosciences, 8(7): 4365-4378.

He Y, Gao J, Yao T et al., 2015a. Spatial distribution of stable isotope in precipitation upon the Tibetan Plateau analyzed with various interpolation methods. Journal of Glaciology and Geocryology, 37(2): 351-359. (in Chinese)

He Y, Risi C, Gao J et al., 2015b. Impact of atmospheric convection on south Tibet summer precipitation isotopologue composition using a combination of in situ measurements, satellite data, and atmospheric general circulation modeling. Journal of Geophysical Research: Atmospheres, 120(9): 3852-3871.

Hou S, Qin D, Mayewski PA et al., 1999. Climatological significance of $\delta^{18} \mathrm{O}$ in precipitation and ice cores: A case study at the head of Urumqi River, Tien Shan, China. Journal of Glaciology, 45(151): 517-523.

$\mathrm{Hu}$ Y, Liu C, Lu Y et al., 2014. Application of environmental isotopes in understanding hydrological processes of the Heihe River Basin. Advances in Earth Science, 29(10): 1158-1166. (in Chinese)

Huang Y, Zhang X, Sun J et al., 2015. Seasonal variations of stable isotope in precipitation and atmospheric water vapor and their relationship with moisture transportation in Changsha City. Scientia Geographica Sinica, 35(4): 498-506. (in Chinese)

Huang Y, Zhang X, Tang F et al., 2013. Variations of precipitation stable isotope and vapor origins revealed by deuterium excess in Changsha. Journal of Natural Resources, 28(11): 1945-1954. (in Chinese)

IAEA, 1990. Environmental Isotope Data No.9: World Survey of Isotope Concentration in Precipitation (1984-1987) (Technique Reports Series No.311). Vienna: IAEA.

IAEA, 1994. Environmental Isotope Data No.10: World Survey of Isotope Concentration in Precipitation (19881991) (Technique Reports Series No. 371). Vienna: IAEA.

IAEA/WMO, 2015. Global Network of Isotopes in Precipitation. 2015-11-29. http://www.iaea.org/water.

Jin X, Zhang M, Wang S et al., 2015. Effect of below-cloud secondary evaporation in precipitations over the Loess Plateau based on the stable isotopes of hydrogen and oxygen. Environmental Science, 36(4): 1241-1248. (in Chinese)

Kang S, Zhang Y, Qin D et al., 2007. Recent temperature increase recorded in an ice core in the source region of Yangtze River. Chinese Science Bulletin, 52(6): 825-831.

Kong Y, Pang Z, Froehlich K, 2013. Quantifying recycled moisture fraction in precipitation of an arid region using deuterium excess. Tellus B, 65: 19251. doi: 10.3402/tellusb.v65i0.19251.

Li G, Zhang X, Zhang L et al., 2015. Stable isotope characteristics in different water bodies in Changsha and implications for the water cycle. Environmental Science, 36(6): 2094-2101. (in Chinese)

Li J, Pang Z, Kong Y et al., 2014. Contrasting seasonal distribution of stable isotopes and deuterium excess in precipitation over China. Fresenius Environmental Bulletin, 23(9): 2074-2085.

Li J, Tao T, Pang Z et al., 2015. Identification of different moisture sources through isotopic monitoring during a storm event. Journal of Hydrometeorology, 16(4): 1918-1927.

Li T, Li H, Shen $\mathrm{C}$ et al., 2010. Study on the $\delta \mathrm{D}$ and $\delta^{18} \mathrm{O}$ characteristics of meteoric precipitation during 2006-2008 in Chongqing, China. Advances in Water Science, 21(6): 757-764. (in Chinese)

Li Y, Zhang M, Li Z et al., 2011a. Seasonal variations of stable oxygen isotope in surface snow and vapor transportation at the headwaters of Urumqi River, Tianshan Mountains. Geographical Research, 30(5): 953-962. (in Chinese)

Li Y, Zhang M, Li Z et al., 2011b, Relationship between profile features of $\delta^{18} \mathrm{O}$ in snow pits over a mountain glacier and local climate: A case study on Glacier No. 1 at the headwaters of the Urumqi River in the Tianshan 
Mountains. Arid Zone Research, 28(6): 950-956. (in Chinese)

Li Y, Zhang M, Wang S et al., 2011c. Spatial distribution of $\delta^{18} \mathrm{O}$ in China's precipitation based on a secondary variable of temperature. Progress in Geography, 30(11): 1387-1394. (in Chinese)

Li Z, Feng Q, Liu W et al., 2015a. The stable isotope evolution in Shiyi glacier system during the ablation period in the north of Tibetan Plateau, China. Quaternary International, 380/381: 262-271.

Li Z, Gao Y, Wang Y et al., 2015b. Can monsoon moisture arrive in the Qilian Mountains in summer? Quaternary International, 358: 113-125.

Liao C, Zhong W, Ma Q et al., 2012. Moisture sources of Guangzhou during the freezing disaster period in 2008 indicated by the stable isotopes of precipitation. Environmental Science, 33(4): 1050-1056. (in Chinese)

Lin G, 2013. Stable Isotope Ecology. Beijing: Higher Education Press. (in Chinese)

Liu D, Chen Z, Luo K, 1987. A study on hydrogen and oxygen isotopic composition of the precipitation in Guilin area. Carsologica Sinica, 6(3): 225-231. (in Chinese)

Liu J, Liu E, Zhao Y et al., 1997a. Analysis of the chief factors influencing the stability isotope composition of China atmospheric precipitation. Site Investigation Science and Technology, (4): 14-18. (in Chinese)

Liu J, Song X, Sun X et al., 2009. Isotopic composition of precipitation over arid northwestern China and its implications for the water vapor origin. Journal of Geographical Sciences, 19(2): 164-174.

Liu J, Song X, Yuan G et al., 2008. Stable isotopes of summer monsoonal precipitation in southern China and the moisture sources evidence from $\delta^{18} \mathrm{O}$ signature. Journal of Geographical Sciences, 18(2): 155-165.

Liu J, Song X, Yuan G et al., 2010. Characteristics of $\delta^{18} \mathrm{O}$ in precipitation over Eastern Monsoon China and the water vapor sources. Chinese Science Bulletin, 55(2): 200-211.

Liu J, Song X, Yuan G et al., 2014. Stable isotopic compositions of precipitation in China. Tellus B, 66: 22567. doi: 10.3402/tellusb.v66.22567.

Liu J, Zhao Y, Liu E et al., 1997b. Discussion on the stable isotope time-space distribution law of China atmospheric precipitation. Site Investigation Science and Technology, (3): 34-39. (in Chinese)

Liu W, Peng X, Shen Y et al., 2013. Measurements of hydrogen and oxygen isotopes in liquid water by isotope ratio infrared spectroscopy (IRIS) and their spectral contamination corrections. Chinese Journal of Ecology, 32(5): 1181-1186. (in Chinese)

Liu X, Rao Z, Zhang X et al., 2015. Variations in the oxygen isotopic composition of precipitation in the Tianshan Mountains region and their significance for the Westerly circulation. Journal of Geographical Sciences, 25(7): $801-816$.

Liu X, Song X, Xia J et al., 2005. A study on oxygen isotope in precipitation of Dongtaigou basin in Chao and Bai river basin. Geographical Research, 24(2): 196-205. (in Chinese)

Liu X, Song X, Xia J et al., 2007. Characteristics of hydrogen and oxygen isotopes and preliminary analysis of vapor source for precipitation in Chabagou Catchment of the Loess Plateau. Resources Science, 29(3): 59-66. (in Chinese)

Liu Z, Tian L, Chai X et al., 2008a. A model-based determination of spatial variation of precipitation $\delta^{18} \mathrm{O}$ over China. Chemical Geology, 249(1/2): 203-212.

Liu Z, Tian L, Yao T et al., 2007. Temporal and spatial variations of $\delta^{18} \mathrm{O}$ in precipitation of the Yarlung Zangbo River Basin. Journal of Geographical Sciences, 17(3): 317-326.

Liu Z, Tian L, Yao T et al., 2008b. Seasonal deuterium excess in Nagqu precipitation: Influence of moisture transport and recycling in the middle of Tibetan Plateau. Environmental Geology, 55(7): 1501-1506.

Liu Z, Tian L, Yao T et al., 2009. Spatial distribution of $\delta^{18} \mathrm{O}$ in precipitation over China. Chinese Science Bulletin, 54(6): 804-811. (in Chinese)

Liu Z, Tian L, Yao T et al., 2010. Characterization of precipitation $\delta^{18} \mathrm{O}$ variation in Nagqu, central Tibetan Plateau and its climatic controls. Theoretical and Applied Climatology, 99(1): 95-104.

Liu Z, Yoshimura K, Kennedy C D et al., 2014. Water vapor $\delta$ D dynamics over China derived from SCIAMACHY satellite measurements. Science China: Earth Sciences, 57(4): 813-823.

Luo W, Wang S, Liu X, 2008. Regional characteristics of modern precipitation $\delta^{18} \mathrm{O}$ values and implications for paleoclimate research in China. Earth and Environment, 36(1): 47-55. (in Chinese) 
Luo W, Wang S, Xie X, 2013. A comparative study on the stable isotopes from precipitation to speleothem in four caves of Guizhou, China. Chemie der Erde - Geochemistry, 73(2): 205-215.

Luo W, Wang S, Zeng G et al., 2014. Daily response of drip water isotopes to precipitation in Liangfeng Cave, Guizhou Province, SW China. Quaternary International, 349: 153-158.

Ma J, Zhang P, Zhu G et al., 2012. The composition and distribution of chemicals and isotopes in precipitation in the Shiyang River system, northwestern China. Journal of Hydrology, 436/437: 92-101.

Ma Q, Zhang M, Wang S et al., 2014. An investigation of moisture sources and secondary evaporation in Lanzhou, Northwest China. Environmental Earth Sciences, 71(8): 3375-3385.

Ma Q, Zhang M, Wang S et al., 2012. Contributions of local moisture to precipitations in Western China. Progress in Geography, 31(11): 1452-1459. (in Chinese)

Ma Q, Zhang M, Wang S et al., 2013. Contributions of moisture from local evaporation to precipitations in Southeast China based on hydrogen and oxygen isotopes. Progress in Geography, 32(11): 1712-1720. (in Chinese)

Meng Y, Liu G, 2010. Effect of below-cloud secondary evaporation on the stable isotopes in precipitation over the Yangtze River basin. Advances in Water Science, 21(3): 327-334. (in Chinese)

Pang H, He Y, Lu A et al., 2006. Synoptic-scale variation of $\delta^{18} \mathrm{O}$ in summer monsoon rainfall at Lijiang, China. Chinese Science Bulletin, 51(23): 2897-2904.

Pang S, Zhao S, Wen R et al., 2015. Spatial and temporal variation of stable isotopes in precipitation in the Haihe River basin. Chinese Science Bulletin, 60(13): 1218-1226. (in Chinese)

Pang Z, Kong Y, Froehlich K et al., 2011. Processes affecting isotopes in precipitation of an arid region. Tellus B, 63(3): 352-359.

Peng L, Li T, 2012. Research progress of monitoring for dripping water environment in karst caves. Carsologica Sinica, 31(3): 316-326. (in Chinese)

Peng T R, Huang C C, Wang C H et al., 2012. Using oxygen, hydrogen, and tritium isotopes to assess pond water's contribution to groundwater and local precipitation in the pediment tableland areas of northwestern Taiwan. Journal of Hydrology, 450/451: 105-116.

Peng T R, Liu K K, Wang C H et al., 2011. A water isotope approach to assessing moisture recycling in the island-based precipitation of Taiwan: A case study in the western Pacific. Water Resources Research, 47(8): W08507. doi: 10.1029/2010WR009890.

Peng T R, Wang C H, Huang C C et al., 2010. Stable isotopic characteristic of Taiwan's precipitation: A case study of western Pacific monsoon region. Earth and Planetary Science Letters, 289(3/4): 357-366.

Ren W, Yao T, Yang X et al., 2013. Implications of variations in $\delta^{18} \mathrm{O}$ and $\delta \mathrm{D}$ in precipitation at Madoi in the eastern Tibetan Plateau. Quaternary International, 313/314: 56-61.

Risi C, Noone D, Worden J et al., 2012. Process-evaluation of tropospheric humidity simulated by general circulation models using water vapor isotopologues: 1. Comparison between models and observations. Journal of Geophysical Research, 117(D5): D05303. doi: 10.1029/2011JD016621.

Song C, Sun X, Wang G, 2015. A study on precipitation stable isotopes characteristics and vapor sources of the subalpine Gongga Mountain, China. Resources and Environment in the Yangtze Basin, 24(11): 1860-1869. (in Chinese)

Song L, Hou S, Liu Y, 2011. $\delta^{18}$ O record of the Miaoergou ice core from the Karlik mountains of east Tienshan since 1953. Journal of Lanzhou University (Natural Sciences), 47(5): 36-41. (in Chinese)

Song X, Liu J, Sun X et al., 2007. Establishment of Chinese Network of Isotopes in Precipitation (CHNIP) based on CERN. Advances in Earth Science, 22(7): 738-747. (in Chinese)

Tan L, Cai Y, Cheng H et al., 2015. Climate significance of speleothem $\delta^{18} \mathrm{O}$ from central China on decadal timescale. Journal of Asian Earth Sciences, 106: 150-155.

Tan M, 2014. Circulation effect: Response of precipitation $\delta^{18} \mathrm{O}$ to the ENSO cycle in monsoon regions of China. Climate Dynamics, 42(3): 1067-1077.

Tan M, Nan S, 2010. Primary investigation on interannual changes in the circulation effect of precipitation oxygen isotopes in monsoon China. Quaternary Sciences, 30(3): 620-622. (in Chinese) 
Tang Y, Pang H, Zhang W et al., 2015. Effects of changes in moisture source and the upstream rainout on stable isotopes in summer precipitation: A case study in Nanjing, East China. Hydrology and Earth System Sciences, 19: 4293-4306.

Tao T, Tan M, Duan W, 2013. Circulation effect on the shortest time scale: Multiple water sources traced by $\delta^{18} \mathrm{O}$ during single precipitation event. Quaternary Sciences, 33(30): 615-617. (in Chinese)

Tian L, Ma L, Yu W et al., 2008. Seasonal variations of stable isotope in precipitation and moisture transport at Yushu, eastern Tibetan Plateau. Science in China Series D: Earth Sciences, 51(8): 1121-1128.

Tian L, Yao T, Li Z et al., 2006. Recent rapid warming trend revealed from the isotopic record in Muztagata ice core, Eastern Pamirs. Journal of Geophysical Research, 111(D13): D13103. doi: 10.1029/2005JD00624.

Tian L, Yao T, MacClune K et al., 2007. Stable isotopic variations in west China: A consideration of moisture sources. Journal of Geophysical Research, 112(D10): D10112. doi: 10.1029/2006JD007718.

$\mathrm{Tu}$ L, Wang H, Feng Y, 2004. Research on $\delta \mathrm{D}$ and ${ }^{18} \mathrm{O}$ isotope in the precipitation of Guilin. Carsologica Sinica, 23(4): 304-309. (in Chinese)

Wang L, Li Z, Dong Z et al., 2011. Chronology and record formation process of an ice core from Glacier No. 1 at the Urumqi Riverhead in eastern Tianshan, China. Arid Land Geography, 34(5): 739-746. (in Chinese)

Wang N, Thompson L G, Davis M E et al., 2003. Influence of variations in NAO and SO on air temperature over the northern Tibetan Plateau as recorded by $\delta^{18} \mathrm{O}$ in the Malan ice core. Geophysical Research Letters, 30(22): 2167. doi: 10.1029/2003GL018188.

Wang N, Zhang S, Pu J et al., 2008. Seasonal variation of $\delta^{18} \mathrm{O}$ in river water in the upper reaches of Heihe River Basin and its influence factors. Journal of Glaciology and Geocryology, 30(6): 914-920. (in Chinese)

Wang S, 2015. Stable hydrogen and oxygen isotopes in precipitation of the Tianshan Mountains and their significance in hydrological cycle [D]. Lanzhou: Northwest Normal University. (in Chinese)

Wang S, Zhang M, Chen F et al., 2015. Comparison of GCM-simulated isotopic compositions of precipitation in arid Central Asia. Journal of Geographical Sciences, 25(7): 771-783.

Wang S, Zhang M, Che Y et al., 2016a. Contribution of recycled moisture to precipitation in oases of arid central Asia: a stable isotope approach. Water Resources Research, 52(4): 3246-3257. doi: 10.1002/2015WR018135.

Wang S, Zhang M, Che Y et al., 2016b. Influence of below-cloud evaporation on deuterium excess in precipitation of arid central Asia and its meteorological controls. Journal of Hydrometeorology. doi: 10.1175/JHM-D-15-0203.1.

Wang S, Zhang M, Hughes C E et al., 2016c. Factors controlling stable isotope composition of precipitation in arid conditions: An observation network in the Tianshan Mountains, central Asia. Tellus B, 68: 26206. doi: 10.3402/tellusb.v68.26206.

Wang X, Li Z, Tayier R et al., 2015. Characteristics of atmospheric precipitation isotopes and isotopic evidence for the moisture origin in Yushugou River basin, Eastern Tianshan Mountains, China. Quaternary International, 380/381: 106-115.

Wei K, Lin R, Wang Z, 1982. Compositions of ${ }^{2} \mathrm{H},{ }^{18} \mathrm{O}$, and ${ }^{3} \mathrm{H}$ in precipitation in Beijing area. Scientia Sinica (Series B), 12(8): 754-757. (in Chinese)

Wen R, Tian L, Weng Y et al., 2012. The altitude effect of $\delta^{18} \mathrm{O}$ in precipitation and river water in the Southern Himalayas. Chinese Science Bulletin, 57(14): 1693-1698.

Wen X F, Lee X, Sun X M et al., 2012. Inter-comparison of four commercial analyzers for water vapor isotope measurement. Journal of Atmospheric and Oceanic Technology, 29(2): 235-247.

Wen X F, Zhang S C, Sun X M et al., 2010. Water vapor and precipitation isotope ratios in Beijing, China. Journal of Geophysical Research, 115(D1): D01103. doi: 10.1029/2009JD012408.

$\mathrm{Wu} \mathrm{H}, \mathrm{Li} \mathrm{X}$, Zhao G et al., 2014a. The variation characteristics of $\delta^{18} \mathrm{O}$ and $\delta \mathrm{D}$ in precipitation and river water, Qinghai Lake Basin. Journal of Natural Resources, 29(9): 1552-1564. (in Chinese)

Wu H, Zhang X, Guan H et al., 2012. Influence of different moisture sources on $\delta \mathrm{D}$ and $\delta^{18} \mathrm{O}$ in precipitation in Changsha, Hunan Province. Journal of Natural Resources, 27(8): 1404-1414. (in Chinese)

Wu H, Zhang X, Li X et al., 2014b. The variations of $\delta^{18} \mathrm{O}$ and $\delta \mathrm{D}$ in different water bodies of Changsha region, middle-and-low reach of the Xiangjiang River. Scientia Geographica Sinica, 34(4): 488-495. (in Chinese) 
Wu H, Zhang X, Li X et al., 2015. Seasonal variations of deuterium and oxygen-18 isotopes and their response to moisture source for precipitation events in the subtropical monsoon region. Hydrological Processes, 29(1): 90-102.

Wu J, Ding Y, Ye B et al., 2010. Spatio-temporal variation of stable isotopes in precipitation in the Heihe River basin, northwestern China. Environmental Earth Sciences, 61(6): 1123-1134.

Wu J, Ding Y, Ye B et al., 2012. Stable isotopes in precipitation in Xilin River Basin, northern China and their implications. Chinese Geographical Science, 22(5): 531-540.

Wu J, Yang Q, Ding Y et al., 2011. Variations and simulation of stable isotopes in precipitation in the Heihe River Basin. Environmental Science, 32(7): 1857-1866. (in Chinese)

Wu X, Zhu X, Pan M et al., 2014. Seasonal variability of oxygen and hydrogen stable isotopes in precipitation and cave drip water at Guilin, southwest China. Environmental Earth Sciences, 72(8): 3183-3191.

Xie L, Wei G, Deng W et al., 2011. Daily $\delta^{18} \mathrm{O}$ and $\delta \mathrm{D}$ of precipitations from 2007 to 2009 in Guangzhou, South China: Implications for changes of moisture sources. Journal of Hydrology, 400(3/4): 477-489.

Xu Q, Liu S, An S et al., 2006. Study on hydrogen and oxygen stable isotopes in precipitation in Wolong Nature Reserve, Sichuan Province. Forest Research, 19(6): 679-686. (in Chinese)

Xu Y, Kang S, Zhang Y et al., 2011. A method for estimating the contribution of evaporative vapor from the Lake Nam Co to local atmospheric vapor based on stable isotopes of water bodies. Chinese Science Bulletin, 56(14): 1511-1517.

$\mathrm{Xu}$ Z, Liu Y, Wang Z et al., 2008. Relationships between stable isotopes in precipitation in Wolong and monsoon activity. Environmental Science, 29(4): 1007-1013. (in Chinese)

Xue J, Zhong W, Zhao Y, 2007. Variations of $\delta^{18} \mathrm{O}$ in precipitation in the Zhujiang (Pearl) River Delta and its relationship with ENSO event. Scientia Geographica Sinica, 27(6): 825-830. (in Chinese)

Xue J, Zhong W, Zhao Y, 2008. Stable oxygen isotope in precipitation in Guangzhou in relation to the meteorological factors and the monsoon activity. Journal of Glaciology and Geocryology, 30(5): 761-768. (in Chinese)

Yang H, Wang H, Ying Q et al., 2012. The impact of hydrogen and oxygen isotope mass fractionation for different detection methods. Rock and Mineral Analysis, 31(2): 225-228. (in Chinese)

Yang J, Qin X, Wu J et al., 2014. The application of modified BW method in studying spatial distribution of $\delta^{18} \mathrm{O}$ in precipitation over China. Journal of Glaciology and Geocryology, 36(6): 1430-1439. (in Chinese)

Yang X, Yao T, Yang W et al., 2011. Co-existence of temperature and amount effects on precipitation $\delta^{18} \mathrm{O}$ in the Asian monsoon region. Geophysical Research Letters, 38(21): L21809. doi: 10.1029/2011GL049353.

Yao T, Duan K, Xu B et al., 2002. Temperature and methane changes over the past 1000 years recorded in Dasuopu glacier (central Himalaya) ice core. Annals of Glaciology, 35(1): 379-383.

Yao T, Guo X, Thompson L G et al., 2006. $\delta^{18} \mathrm{O}$ record and temperature change over the past 100 years in ice cores on the Tibetan Plateau. Science in China Series D: Earth Sciences, 49(1): 1-9.

Yao T, Masson V, Jouzel J et al., 1999. Relationships between $\delta^{18} \mathrm{O}$ in precipitation and surface air temperature in the Urumqi River Basin, East Tianshan Mountains, China. Geophysical Research Letters, 26(23): 3473-3476.

Yao T, Masson-Delmotte V, Gao J et al., 2013. A review of climatic controls on $\delta^{18} \mathrm{O}$ in precipitation over the Tibetan Plateau: Observations and simulations. Reviews of Geophysics, 51(4): 525-548.

Yao T, Thompson L G, 1992. Trends and features of climatic changes in the past 5000 years recorded by the Dunde ice core. Annals of Glaciology, 16(1): 21-24.

Yao T, Thompson L G, Qin D et al., 1996. Variations in temperature and precipitation in the past 2000 a on the Xizang (Tibet) Plateau: Guliya ice core record. Science in China (Series D), 39(4): 425-433.

Yao T, Zhou H, Yang X, 2009. Indian monsoon influences altitude effect of $\delta^{18} \mathrm{O}$ in precipitation/river water on the Tibetan Plateau. Chinese Science Bulletin, 54(16): 2724-2731.

Yin H, Zhong W, Ma Q et al., 2012. Variational characteristics of $\delta^{18} \mathrm{O}$ in precipitation in Guangzhou under extreme weather events. Journal of South China Normal University (Natural Science Edition), 44(4): 121-127. (in Chinese)

Yin $\mathrm{L}$, Hou $\mathrm{G}, \mathrm{Su} \mathrm{X}$ et al., 2011. Isotopes $\left(\delta \mathrm{D}\right.$ and $\left.\delta^{18} \mathrm{O}\right)$ in precipitation, groundwater and surface water in the 
Ordos Plateau, China: Implications with respect to groundwater recharge and circulation. Hydrogeology Journal, 19(2): 429-443.

Yu J, Li Y, 1997. Isotope Geochemistry Studies in China. Beijing: Science Press. (in Chinese)

$\mathrm{Yu}$ W, Ma Y, Sun W et al., 2009. Climatic significance of $\delta^{18} \mathrm{O}$ records from precipitation on the western Tibetan Plateau. Chinese Science Bulletin, 54(16): 2732-2741.

Yu W, Tian L, Ma Y et al., 2006. Advances in the study of stable oxygen isotope in precipitation on the Tibetan Plateau. Advances in Earth Science, 21(12): 1314-1323. (in Chinese)

Yu W, Tian L, Ma Y et al., 2015a. Simultaneous monitoring of stable oxygen isotope composition in water vapour and precipitation over the central Tibetan Plateau. Atmospheric Chemistry and Physics, 15: 10251-10262.

Yu W, Wei F, Ma Y et al., 2016. Stable isotope variations in precipitation over Deqin on the southeastern margin of the Tibetan Plateau during different seasons related to various meteorological factors and moisture sources. Atmospheric Research, 170: 123-130. doi: 10.1016/j.atmosres.2015.11.013.

Yu W, Yao T, Lewis S et al., 2014. Stable oxygen isotope differences between the areas to the north and south of Qinling Mountains in China reveal different moisture sources. International Journal of Climatology, 34(6): 1760-1772.

Yu W, Yao T, Tian L et al., 2007. Stable isotope variations in precipitation and moisture trajectories on the western Tibetan Plateau, China. Arctic, Antarctic, and Alpine Research, 39(4): 688-693.

Yu W, Yao T, Tian L et al., 2008. Relationships between $\delta^{18} \mathrm{O}$ in precipitation and air temperature and moisture origin on a south-north transect of the Tibetan Plateau. Atmospheric Research, 87(2): 158-169.

Yu W, Yao T, Tian L et al., 2015b. Short-term variability in the dates of the Indian monsoon onset and retreat on the southern and northern slopes of the central Himalayas as determined by precipitation stable isotopes. Climate Dynamics. doi: 10.1007/s00382-015-2829-1.

Zeng G, Luo W, Wang S et al., 2015. Hydrogeochemical and climatic interpretations of isotopic signals from precipitation to drip waters in Liangfeng Cave, Guizhou Province, China. Environmental Earth Sciences, 74(2): 1509-1519.

Zhai Y, Wang J, Zhang Y et al., 2013. Hydrochemical and isotopic investigation of atmospheric precipitation in Beijing, China. Science of the Total Environment, 456/457: 202-211.

Zhang D, Qin D, Hou S et al., 2005. Climatic significance of $\delta^{18} \mathrm{O}$ records from an $80.36 \mathrm{~m}$ ice core in the East Rongbuk Glacier, Mount Qomolangma (Everest). Science in China Series D: Earth Sciences, 48(2): $266-272$.

Zhang H, 1989. Research on background value of stable isotope in precipitation of China. Site Investigation Science and Technology, (6): 62-12. (in Chinese)

Zhang H, Liu E, Wang D et al., 1991. Isotopic composition of stable isotope in precipitation of China and the influencing factors. Proceedings of Institute of Hydrogeology and Engineering Geology, Chinese Academy of Geological Sciences, 7: 101-110. (in Chinese)

Zhang L, Han M, Jia Y et al., 2015. Analysis of hydrogen and oxygen isotope in water sample using isotope ratio mass spectrometry and laser spectroscopy. Journal of Chinese Mass Spectrometry Society, 36(6): 559-564. (in Chinese)

Zhang M, Zhou P, Li Z et al., 2009. Evolution processes of $\delta^{18} \mathrm{O}$ in snowpits on No. 1 glacier at the Urumqi river head, Tianshan Mountains. Journal of Lanzhou University (Natural Sciences), 45(5): 36-40. (in Chinese)

Zhang M, Zhu X, Wu X et al., 2015. $\delta^{18} \mathrm{O}$ characteristics of meteoric precipitation and its water vapor sources in the Guilin area of China. Environmental Earth Sciences, 74(2): 953-976.

Zhang S, Yu W, Zhang Q et al., 1973. Distribution of isotopes in some natural waters in the region north of Mt. Jolmo Lungma. Scientia Sinica, 16(4): 560-564.

Zhang X, Liu J, Tian L et al., 2004. Variations of $\delta^{18} \mathrm{O}$ in precipitation along vapor transport paths. Advances in Atmospheric Sciences, 21(4): 562-572.

Zhang X, Sun Z, Guan H et al., 2012. GCM simulations of stable isotopes in the water cycle in comparison with GNIP observations over East Asia. Acta Meteorologica Sinica, 26(4): 420-437.

Zhang X, Xie Z, Yao T, 1998. Mathematical modeling of variations on stable isotopic ratios in falling raindrops. Acta Meteorologica Sinica, 12(2): 213-220. 
Zhang X, Yao T, 1998. Distributional features of $\delta^{18} \mathrm{O}$ in precipitation in China. The Journal of Chinese Geography, 8(2): 57-64.

Zhang X, Yao T, Liu J, 2003. Oxygen-18 in different waters in Urumqi River Basin. Journal of Geographical Sciences, 13(4): 438-446.

Zhang X P, Guan H D, Zhang X Z et al., 2015. Simulation of stable water isotopic composition in the atmosphere using an isotopic Atmospheric Water Balance Model. International Journal of Climatology, 35(6): 846-859.

Zhang X P, Liu J M, Wang X Y et al., 2010. Climatological significance of stable isotopes in precipitation over south-west China. International Journal of Climatology, 30(14): 2229-2239.

Zhang Y, Wu Y, 2007a. Characteristics of the $\delta^{18} \mathrm{O}$ in precipitation in the upper and middle reaches of Heihe River. Journal of Glaciology and Geocryology, 29(3): 440-445. (in Chinese)

Zhang Y, Wu Y, 2007b. Relation between oxygen and hydrogen isotopes in precipitation and temperature in Heihe river basin, China. Arid Land Geography, 30(1): 16-21. (in Chinese)

Zhao H, Xu B, Wang N, 2014. Study on the water stable isotopes in Tibetan Plateau ice cores as a proxy of temperature. Quaternary Sciences, 34(6): 1215-1226. (in Chinese)

Zhao H, Xu B, Yao T et al., 2012. Deuterium excess record in a southern Tibetan ice core and its potential climatic implications. Climate Dynamics, 38(9): 1791-1803.

Zhao K, Gu W, Gu W et al., 1995. Precipitation Isotope Network in China. Journal of China Hydrology, 15(5): 25-27. (in Chinese)

Zhao L, Xiao H, Zhou J et al., 2011a. Detailed assessment of isotope ratio infrared spectroscopy and isotope ratio mass spectrometry for the stable isotope analysis of plant and soil waters. Rapid Communications in Mass Spectrometry, 25(20): 3071-3082.

Zhao L, Xiao H, Zhou M et al., 2012. Factors controlling spatial and seasonal distributions of precipitation $\delta^{18} \mathrm{O}$ in China. Hydrological Processes, 26(1): 143-152.

Zhao L, Yin L, Xiao H et al., 2011b. Isotopic evidence for the moisture origin and composition of surface runoff in the headwaters of the Heihe River basin. Chinese Science Bulletin, 56(4): 406-415.

Zhao S, Pang S, Wen R et al., 2015. Influence of below-cloud secondary evaporation on stable isotope composition in precipitation in the Haihe River Basin, China. Progress in Geography, 34(8): 1031-1038. (in Chinese)

Zheng S, Hou F, Ni B, 1983. Research on stable hydrogen and oxygen isotopes in precipitation of China. Kexue Tongbao, 28(13): 801-806. (in Chinese)

Zheng Y, Chen J, 2000. Stable Isotope Geochemistry. Beijing: Science Press. (in Chinese)

Zheng Y, Zhong W, Peng X et al., 2009. Correlation of $\delta^{18} \mathrm{O}$ in precipitation and moisture sources at Yunfu, western Guangdong Province, China. Environmental Science, 30(3): 637-643. (in Chinese) 